\title{
Multiculturalismo e educação inclusiva: contribuições da universidade para a formação continuada de professores de escolas públicas no Rio de Janeiro
}

Giseli Pereli de Moura Xavier ${ }^{*}$ Ana Canen **

Resumo: A presente pesquisa parte do argumento de que a educação inclusiva poderia beneficiarse da perspectiva multicultural, que questiona formas de ocultação das diferenças de modo a desafiar preconceitos e processos de exclusão de grupos socioculturais oprimidos, no contexto educacional. Nesse sentido, o objetivo foi compreender possibilidades dessa articulação tanto em nível teórico, como a partir da análise de uma experiência extensionista de formação continuada para coordenadores pedagógicos, na rede estadual de educação do Rio de Janeiro, tomada como estudo de caso. Para tanto, explicitamos as bases teóricas do estudo e, em seguida, analisamos os dados da pesquisa, em termos das visóes iniciais dos docentes sobre a temática; o teor do curso contido nos materiais; os debates realizados; a avaliação final dos potenciais e os desafios suscitados. Os resultados indicam a fertilidade das açôes extensionistas da universidade na configuração da formação continuada para uma educação inclusiva multicultural.

Palavras-chave: formação continuada docente; educação inclusiva; multiculturalismo; estudo de caso; coordenadores pedagógicos.

\section{Multiculturalism and inclusive education: university contributions to continuing education for teachers in public schools in Rio de Janeiro}

Abstract: The present research is based on the argument that inclusive education could benefit from a multicultural perspective, with the questioning of mechanisms that hide differences, so as to challenge prejudices and processes that seclude oppressed socio-cultural groups in educational contexts. The aim of the research was to understand possibilities of working out this concept both in theoretical termsandwith the analysis ofan extensionistic experience of extended teacher education for pedagogical coordinators in the state of Rio de Janeiro, taken as a case study. We firstly structure the theoretical framework of the study; then, we analyze the research data for the teachers' first impressions about the topics, as well as the course contents and materials and the ideas discussed, and we finally evaluate the potentials and challenges

* Professora Assistente da Escola de Educação e Meio Ambiente (UniverCidade/RJ) e doutoranda em educação da Faculdade de Educação/UFRJ. titogigi@uol.com.br.

* Professora do Departamento Fundamentos da Educação, Universidade Federal do Rio de Janeiro/UFRJ, Pesquisadora do CNPq. acanen@globo.com. 
aroused by that experience. The results point to the fertility of extensionistic university actions in continuing teacher education for inclusive, multicultural education.

Key words: teacher continuing education; inclusive education; multiculturalism; case study; pedagogical coordinators.

\section{Introdução}

Pensar sobre a formação continuada de profissionais da educação e a importância da universidade nesse empreendimento significa pensar em formas de promover o diálogo entre a academia e as escolas, de modo a auxiliar no crescimento de atores de ambas as instituiçóes e de socializar pesquisas na área educacional. Nesse sentido, a extensão universitária adquire relevo, na medida em que promove impactos no sistema público de ensino, por meio da formação continuada de seus profissionais, e traz atores universitários em contato com a realidade educacional, transformando-a e sendo por ela transformados.

A partir do exposto, o presente artigo estuda o caso de uma pesquisa-ação desenvolvida por uma universidade pública no contexto de um curso de formação continuada para profissionais da educação das escolas públicas do Estado do Rio de Janeiro, Brasil. O curso foi organizado em módulos presenciais, com temas educacionais específicos, dirigido a turmas compostas, em sua maioria, por coordenadores pedagógicos, mas também contando com a presença de diretores, secretários escolares e professores. Cada turma possuía, em média, 25 participantes, sob a responsabilidade de um tutor universitário, que era incumbido da apresentação e da dinamização dos módulos. Nos limites do presente artigo, focalizamos a realização dos encontros referentes ao Módulo Educação Inclusiva em nove turmas do referido curso, nas quais participamos como tutoras, que contemplaram o total de 225 cursistas. As turmas em questão pertencem a regiões com características socioeconômicas e culturais bem diversificadas.

A metodologia da pesquisa-ação foi utilizada a partir da compreensão de seu potencial como construtora de conhecimento por intermédio, como argumentam Miranda \& Resende (2006), da articulação da pesquisa junto à ação, à prática, associada, também, à idéia de mudança, de transformação dos sujeitos. Ao mesmo tempo, consideramos as observações dos referidos autores quanto aos perigos do praticismo, que podem ser minimizados quando se tem em mente que a pesquisa-ação passa, necessariamente, pela mediação teórica na apreensão e transformação da realidade. Nesse sentido, a pesquisa-ação em pauta partiu do referencial teórico do multiculturalismo - entendido como movimento teórico, prático e político, voltado ao desafio a preconceitos, à valorização da diversidade cultural e à tradução dessas perspectivas em temas, es- 
tratégias e práticas educacionais (Canen, 1997; Canen \& Moreira, 1999; Canen \& Xavier, 2005; Canen \& Santos, 2006; Canen \& Canen, 2005).

Tal perspectiva esteve presente no trabalho com os módulos, dos quais aquele dedicado à educação inclusiva é objeto do presente artigo. Para tanto, estruturamos este texto da seguinte forma: em um primeiro momento, apresentamos as bases teóricas do estudo, articulando multiculturalismo e inclusão; em um segundo momento, discutimos os dados da pesquisa, analisando as visões iniciais dos docentes sobre a temática, o teor do curso contido nos materiais e os debates realizados. Concluímos, indicando a fertilidade das ações extensionistas da universidade na configuração de uma educação inclusiva multicultural.

\section{Pensando em educação inclusiva multicultural para a formação de professores: um outro ponto de partida...}

Incluir, na visão de muitos educadores, não é considerado um conceito consensual ou uma tarefa fácil. Na verdade, o verbo incluir, apesar de sua definição aparentemente simples - ato de relacionar, compreender, fazer tomar parte, inserir - encerra múltiplas visões e práticas. No entanto, o conceito de inclusão e as açôes que dele resultam tendem a refletir uma concepção pessoal, política, sociocultural e/ou institucional que se tem sobre a educação e sobre o tipo de sociedade que se deseja.

Conforme explicitado anteriormente, o objeto de estudo desta pesquisa refere-se à análise e à interpretação dos dados colhidos durante a realização dos encontros referentes ao Módulo Educação Inclusiva em nove turmas do curso de formação continuada, nas quais atuamos como tutoras, pertencentes a regióes com características socioeconômicas e culturais bem diversificadas, com um total de 225 participantes. A concepção desenvolvida no módulo em pauta seguia a linha de ação no sentido de articular as ações de formação continuada com reflexões teóricas multiculturais que se estendessem para o currículo em ação e para as práticas didático-pedagógico-curriculares na escola (Canen \& Santos, 2006). O trecho abaixo, retirado do material escrito referente ao módulo, ilustra a perspectiva por nós abraçada:

Assim, neste módulo, caminharemos norteados por uma corrente que valoriza a diversidade cultural das escolas - o Multiculturalismo Crítico, Interculturalismo Crítico ou Perspectiva Intercultural Crítica - e que preconiza que entendamos os processos de inclusão e de exclusão a partir da compreensão de como a noção de "diferença" é produzida nos contextos social e escolar, a partir de suas relaçóes de poder e de suas 
representações sociais, procurando vislumbrar novas rotas e ações que permitam criar espaços (voz e vez) para os grupos que se encontram marcados pelo estigma do preconceito, da discriminação e da exclusão.

Para tanto, este módulo discutirá a concepção de "educação inclusiva multicultural" a partir dos seus conceitos, práticas, potenciais, benefícios, limites e bases legais, como podemos ver nos objetivos descritos a seguir:

- Analisar criticamente os desafios e limites de uma educação inclusiva e multicultural.

- Discutir e identificar os potenciais multiculturais críticos da Educação Inclusiva.

[...]

- Analisar e configurar uma proposta de intervenção por parte dos coordenadores pedagógicos com intuito de desenvolver uma verdadeira educação inclusiva no cotidiano escolar, a partir de uma perspectiva multicultural crítica. (Xavier, 2005, p.14).

De fato, a discussão teórico-prática apresentada no módulo buscava levar os envolvidos no curso a uma reflexão sobre a temática e sua ação sobre a mesma, procurando desenvolver novas percepções sobre a questão, a partir de um pensamento multicultural crítico. Dentro dessa ótica, o conceito de educação inclusiva era apresentado e analisado à luz de tensões que envolvem as noções inclusão/exclusão e identidade/diferença. Isso porque, no olhar multicultural, não se pode conceber a inclusão sem inseri-la em um processo mais amplo que questiona a exclusão, que interroga sobre a formação das identidades e sobre a construção discursiva das diferenças.

Argumentamos, no material trabalhado, que analisar inclusão significa, no olhar multicultural, entender o significado de exclusão. A exclusão leva a uma suposta, imposta e dolorosa invisibilidade. É como se o excluído não existisse. Suas necessidades, sua cultura e sua realidade parecem distantes e irreais. $\mathrm{Ou}$ talvez, mais do que isso, sejam incomodativas e provocativas em demasia para a preservação de nossa pretensa estabilidade pessoal e social. Essa questão está intimamente ligada às identidades dos indivíduos e grupos, a seus processos de pertencimento e às formas pelas quais se constroem as diferenças, o modo como se constrói a idéia do "outro". De acordo com Silva (2000), a marcação de identidade e diferença é o resultado de uma produção simbólica e discursiva imposta por relações sociais e de poder assimétricas. Essa marcação entre identidade e diferença envolve todo um processo de hierarquização e de classificação dos indivíduos e dos grupos, estabelecido por meio de oposições binárias: eu/ele; nós/eles; normal/anormal; certo/errado; bons/maus; etc. 
A afirmação da identidade e a marcação da diferença implicam, sempre, as operaçôes de incluir e de excluir. Como vimos, dizer "o que somos" significa também dizer "o que não somos". A identidade e a diferença traduzem-se, assim, em declaraçôes sobre quem pertence e sobre quem não pertence, sobre quem está incluído e sobre quem está excluído. Afirmar a identidade significa demarcar fronteiras; essa separação e distinção supõem e, ao mesmo tempo, afirmam e reafirmam relações de poder. "Nós" e "eles" não são, neste caso, simples distinções gramaticais. Os pronomes "nós" e "eles" não são, aqui, simples categorias gramaticais, mas evidentes indicadores de posições de sujeito fortemente marcadas por relações de poder. (Silva, 2000, p. 82)

$\mathrm{Na}$ relação de alteridade, a identidade hegemônica é aquela que é fixada como normal, desejável. O diferente é o "outro", "aquilo que eu não sou ou que não posso ser" e que, ao mesmo tempo, desestabiliza e assusta, mas sem o qual a identidade não pode se definir e afirmar, uma vez que ela não é absoluta e sim, relacional. Dentro desse princípio, o excluído é sempre o "outro", pois às identidades hegemônicas cabem os privilégios da classificação social, da atribuição de parâmetros e valores e, conseqüentemente, da rejeição e da normalização (Silva, 2000).

A interação com os outros faz com que também se transmita uma imagem de identidade que pode ser aceita ou recusada. Nesse sentido, a identidade implica um processo constante de identificação do "eu" ao redor do outro e do outro em relação ao "eu". O olhar sobre o outro faz aparecer as diferenças e, por estas, a consciência de uma identidade. (D’Adesky, 2005, p. 40)

Nossa perspectiva, no curso, foi a de que, quando falamos em uma educação inclusiva para as nossas escolas, a partir do olhar multicultural, temos que ter em mente dois aspectos importantes: primeiramente, que as diferenças não constituem incompletudes, defeitos, falhas ou caracteres de anormalidade, e sim, que elas se caracterizam como uma pluralidade de formas legítimas de ver, de ser e de estar no mundo. E, em segundo lugar, que se faz necessário e urgente olhar para o interior de nossas salas de aulas, não apenas procurando os que estão ausentes fisicamente desse local, mas também buscando os grupos e os indivíduos a quem os processos educativo e social têm negado espaço, representação, voz, permanência e sucesso.

Dessa forma, incluir deve ser muito mais do que o acesso à educação. Incluir significa possibilidade de acesso, ingresso, permanência, participação, representação e sucesso escolar. Está muito além da caridade, da benevolência e do assistencialismo. A inclusão deve ser uma ação de garantia de direitos constitucionais e educacionais a todos os indivíduos, independentemente de sua origem, classe social, cultura, etnia, gênero, sexualidade, religião, características psicofísicas, etc. 
Canen (2003, p. 50-51) explica que a constituição da identidade a partir de um olhar multicultural crítico deve basear-se em três premissas fundamentais: (1) "a identidade é uma construção contínua, sempre provisória e contingente, constituída e reconstituída em relações sociais", ou seja, não há nesse contexto uma identidade que possa ser considerada única, homogênea ou certa; (2) o desafio à existência de um marcador-mestre identitário, uma vez que a construção da identidade envolve marcadores plurais que "se hibridizam em contextos singulares de significação", formando as chamadas "diferenças dentro das diferenças"; (3) "a sociedade é formada na pluralidade de identidades", o que significa dizer que no "discurso oficial" e nos currículos escolares sempre haverá identidades privilegiadas e silenciadas e que, por isso mesmo, precisamos estar atentos e prontos para transgredi-los, formando "discursos desafiadores da construção das diferenças". Da mesma forma, Canen \& Canen (2005a) alertam que a identidade deve ser percebida em sua tripla dimensão: identidade individual (a que é construída por cada sujeito nas suas histórias e relaçôes sociais); identidade coletiva (a que significa o pertencimento do indivíduo a algum coletivo ou grupo); e a identidade institucional ou organizacional (aquela que caracteriza a instituição ou a organização em que se está inserido, particularmente o clima organizacional).

Assim sendo, falar sobre educação inclusiva multicultural pressupõe, conforme discutimos no curso, uma mudança na cultura organizacional da escola. Reforçamos, na pesquisa-ação desenvolvida, que é preciso repensar as relaçóes sociais, as práticas pedagógicas e os currículos escolares para realizar a inclusão, em uma perspectiva multicultural. Para tanto, é necessário que o trabalho pedagógico se encontre alicerçado em um processo de conscientização cultural (Canen, 1997), entendendo a escola como organização multicultural (Canen $\&$ Canen, 2005b). Alguns pressupostos foram sugeridos para tal trabalho:

- O reconhecimento da escola como um lócus cultural, em que a multiplicidade e a diferença são a sua tônica enriquecedora.

- O desvelamento e a denúncia dos processos excludentes, para que possam ser superados os mecanismos que silenciam e oprimem grupos culturais e identidades excluídas.

- O rompimento com o olhar hierarquizado sobre as diferenças - a não superioridade ou inferioridade de um padrão cultural sobre outros.

- A reflexão sobre a relação entre cultura e poder que perpassa o currículo e suas práticas pedagógicas.

- O desenvolvimento de uma cidadania crítica - capacidade do indivíduo de apropriar-se de seus direitos e fazer valer sua voz de maneira crítica, consciente, solidária e participativa. 
- A promoção do respeito pela diversidade e do trabalho coletivo em prol da justiça social, reduzindo preconceitos e criando atitudes positivas em relação às diferenças.

- O exercício da vigilância sobre seus próprios discursos e práticas, de modo que preconceitos e estereótipos não se "naturalizem".

- A realização de atividades que auxiliem na superação do fracasso escolar, sem discriminar ou rotular os envolvidos, por meio de atitudes de cooperação mútua e valorização dos modos alternativos de cultura.

- O desenvolvimento de um currículo que leve em conta a pluralidade cultural da sociedade e da escola e que tenha o diálogo como base de sua ação, buscando superar os discursos que silenciam ou estereotipam as diferenças. (Xavier, 2005, p.24)

A próxima seção irá trabalhar com as percepções iniciais e as idéias surgidas no decorrer do desenvolvimento do módulo em questão.

Percepções e impactos multiculturais: a educação inclusiva na formação continuada

Os dados a seguir referem-se às percepções e às concepçôes dos cursistas levantadas nas nove turmas, divididas em quatro pólos da região metropolitana do estado do Rio de Janeiro. O grupo de coordenadores pedagógicos era formado por professores com diferentes formações e segmentos de atuação (Educação Infantil, Ensino Fundamental, Ensino Médio, Educação de Jovens e Adultos e Educação Especial).

A dinâmica do curso iniciava com um levantamento das expectativas dos cursistas em relação à temática a ser desenvolvida em cada encontro. Para tanto, os cursistas respondiam a um pequeno questionário composto de três questôes que procuravam esclarecer: (1) o que eles entendiam sobre aquele tema; (2) como eles o estavam vivenciando em suas escolas; e (3) quais eram as suas expectativas em relação ao módulo. As questôes propostas buscavam realizar um brainstorming ou "chuva de idéias", de modo que os cursistas fossem incitados inicialmente a refletir sobre o tema, ao mesmo tempo que forneciam subsídios que permitissem avaliar de que forma a concepção trabalhada foi capaz de modificar (ou não) as concepções iniciais e as práticas pedagógicas dos envolvidos no curso.

Nesse sentido, o método de coleta e categorização dos dados deu-se da seguinte forma: procedeu-se, por um lado, a uma tabulação quantitativa das respostas ao questionário inicial acima explicitado, delineando-se a porcentagem de respostas que evidenciavam (ou não) sensibilidades multiculturais nas 
concepções iniciais, vivências e expectativas com relação à educação inclusiva. O mesmo procedimento foi realizado com relação ao exercício escrito contido ao final do módulo, onde era requisitado, aos cursistas, que descrevessem uma ação desenvolvida em suas escolas após o estudo do módulo. Por outro lado, o estudo baseou-se, também, em dados qualitativos expressos tanto nas respostas às questôes acima, como no exercício proposto e em depoimentos dos participantes durante as discussões realizadas no decorrer dos encontros presenciais, dos quais alguns extratos foram reproduzidos e analisados no presente artigo.

No que se refere ao levantamento das percepçōes iniciais sobre educação inclusiva, os dados demonstraram que, para a maioria dos cursistas (80\%), antes do desenvolvimento do módulo, a expressão educação inclusiva referia-se exclusivamente à inclusão dos Portadores de Necessidades Educacionais Especiais (PNEE). De fato, quando indagados sobre o que entendiam por inclusão, as respostas não variaram muito das que vemos abaixo:

\section{"Alunos com algum tipo de deficiência freqüentando uma turma de alunos sem deficiência." \\ "Inclusão ésaber aceitar, respeitar e (saber) atender aos alunos por- tadores de deficiências fisicas ou mentais, integrando-os ao conví- vio escolar e social, ajudando-os a vencer barreiras, incentivando- os da melhor maneira."}

Ao mesmo tempo, foi possível perceber, em 10\% deste mesmo grupo de respostas, um viés preconceituoso no trato da inclusão dos próprios PNEEs, que eram vistos como um problema ou como incapazes pela escola, como podemos perceber pelas frases transcritas a seguir:

"Incluir alunos na escola, que muitas vezes são vistos como alunos problemas."

"É dar oportunidade aos alunos portadores de necessidades educacionais especiais (em funçāo, por exemplo, de alguma deficiência fisica ou mental) de estudarem nas classes regulares da escola, de acordo com o seu nivel de ensino, tendo assim a oportunidade de conviverem com outras crianças elou jovens que nāo tenham tais problemas."

Nesse sentido, é possível perceber que a educação inclusiva, para muitos educadores, ainda se restringia à inserção/integração dos PNEEs no contexto escolar, integração esta que ainda se encontra "travada" e conectada a preconceitos e estigmas que tendem a rotular esses indivíduos como incapazes, incompletos, alguém a quem faltaria algo. Sobre essa questão Skliar $(1999,2001)$ alerta-nos para os perigos de uma inclusão que ele chama de "excludente", uma vez que, ao invés de trabalhar no sentido de que a escola se adapte aos PNEEs, 
ela reforça os mecanismos sociais que produzem a exclusão e preconiza que os indivíduos devam se adequar a ela. Essa prática acaba levando ao assistencialismo e não à educação, pois reflete uma dinâmica em que as oportunidades são reduzidas por uma visão que considera tais indivíduos incapazes de prosseguir.

Em uma visão multicultural, as diferenças não são vistas como deficits ou falhas, e sim como características que tendem a enriquecer o espaço escolar. Da mesma forma, elas não se resumem às características psicofísicas dos sujeitos. Nessa visão, é valorizada toda diversidade cultural dos sujeitos que formam o espaço escolar, tomando como ponto de partida a superação dos preconceitos, dos processos homogeneizantes, dos binarismos e dos congelamentos identitários (Canen \& Santos, 2006; Canen \& Canen, 2005; Canen \& Xavier, 2005).

É importante ressaltar que apenas $20 \%$ dos participantes das turmas em tela evidenciaram uma compreensão da educação inclusiva mais voltada para o atendimento à diversidade cultural e suas múltiplas diferenças, denotando um viés multicultural:

\footnotetext{
"Valorização de diversidades étnico-culturais, sociais e dos portadores de necessidades educativas especiais no ambiente escolar. Observando e respeitando as diferenças de modo a oportunizar experiências ricas de aprendizagem para todos."

"Ésaber conviver com as diferenças e respeitá-las. É a possibilidade de acesso de todos à educação, independente de suas necessidades educacionais especiais, suas convicções sociais, culturais, pessoais, políticas..."
}

Dentro desse grupo de respostas, surgiram opiniōes que compartilhavam da necessidade de trabalhar o atendimento às diferenças no contexto escolar $\mathrm{e}$ que se traduziam em medidas, tais como: dar oportunidades aos diferentes; resguardar da discriminação; acolher e aceitar o outro; oferecer uma educação de qualidade para todos; reduzir as desigualdades, aprender a conviver com as diferenças; $e$ entender e reconhecer o outro.

Em um segundo momento, quando inquiridos sobre como vinham vivenciando a educação inclusiva em suas escolas, alguns aspectos importantes surgiram. O primeiro grupo, que totalizava $80 \%$ das respostas e que evidenciava uma visão de inclusão associada exclusivamente aos PNEEs, conforme comentado anteriormente, afirmava não poder vivenciar a inclusão devido à falta de condiçôes adequadas para trabalhar e receber os chamados "deficientes" na escola. Dentre os problemas levantados, destacaram-se: a existência de turmas numerosas, a localização da escola, as instalaçôes físicas inadequadas, a falta de uma proposta pedagógica apropriada, os professores sem preparo teórico e técnico, a desmotivação dos professores, a falta de apoio especializado, a falta de colaboração da comunidade escolar e, até mesmo, a ausência de PNEE na escola. 
Já com relação às respostas apresentadas pelos $20 \%$ de cursistas, referidos anteriormente, identificados como mais sensíveis à articulação da inclusão ao multiculturalismo, já se fazia sentir uma preocupação com a questão, que se traduzia em práticas pedagógicas. No entanto, mesmo nesses casos, tais práticas pareciam representar medidas estanques e pontuais, sem grandes perspectivas de continuidade ou aprofundamento, como se percebe no extrato a seguir:

"Temos vivenciado a inclusão, procurando nos sensibilizarmos com oficinas, troca de experiências, capacitaçôes para que a motivação em trabalhar com a diversidade humana seja possivel e prazerosa. Sempre será possivel se nos aceitarmos em nossas diferenças."

Muito embora tenha ficado constatada uma séria preocupação com a questão em pauta, ficou evidenciado de forma clara e na quase totalidade das respostas (96\%) que, nas escolas representadas pelos integrantes do curso, ainda não se configurava verdadeiramente uma educação inclusiva em seus currículos e práticas pedagógico-curriculares. De acordo com Canen \& Moreira (1999, pp.18-19), para que um processo curricular e suas conseqüentes práticas possam estar informados por essa perspectiva inclusiva multicultural crítica, faz-se necessário:

[...] articular a pluralidade cultural mais ampla da sociedade à pluralidade de identidades presentes no contexto concreto da sala de aula [...];

[...] focalizar as diferenças como processo de construção, decodificar teoria e conceitos na perspectiva do outro, bem como desafiar mensagens etnocêntricas, racistas e discriminatórias nos materiais didáticos e nos discursos da sala de aula;

[...] destacar a importância do diálogo como elemento delineador de uma prática curricular multiculturalmente orientada.

Subjacente a essas medidas, a sensibilização daqueles que integram a comunidade escolar para o trabalho com as diferenças, nesse contexto, é condição indispensável para a prática de uma educação inclusiva. É preciso modificar olhares, rever posições pessoais e profissionais, mudar posturas e romper barreiras atitudinais, se quisermos realmente empreender uma educação que se efetive nas suas concepções e práticas como articuladora e valorizadora dessa diversidade.

Em um terceiro momento, ao serem questionados sobre quais eram as suas expectativas sobre o módulo de Educação Inclusiva, ficaram realçadas a vontade e a necessidade que os cursistas tinham de receber subsídios que os auxilias- 
sem a entender e trabalhar a inclusão. Esse fato denotava uma angústia e uma insegurança em relação à questão, ao mesmo tempo que grandes expectativas eram depositadas no módulo que seria desenvolvido no nosso curso, como podemos ver nas respostas que se seguem:

"Espero que este módulo traga uma "luz", no sentido de suavizar
nossas anguistias em relação às dificuldades de se trabalhar com essa
"nova" realidade."
"Nos auxiliar - desmistificar o 'fantasma' da inclusão."

Torna-se importante ressaltar que, ainda com relação às respostas a essa questão, para $52 \%$ dos cursistas, a realização da inclusão, no âmbito escolar, ainda era uma verdadeira incógnita. Apesar de aparentemente conhecerem o seu conceito, esses $52 \%$ de coordenadores pedagógicos não tinham a menor idéia de como agir para efetivar a inclusão em suas escolas. Para muitos era uma novidade, uma "nova realidade" e, por conta disso, havia uma enorme solicitação para que o módulo propiciasse uma troca de experiências, um aprendizado e um embasamento teórico e prático sobre a questão.

Esse aspecto levantado nos faz refletir sobre dois pontos importantes em relação à proposta de educação inclusiva para escolas: o primeiro refere-se à forma como ela vem sendo implementada, de forma vertical pelas políticas públicas, sem maiores esclarecimentos ou debates com a comunidade escolar. O segundo ressalta a questão da "invisibilidade" das demais diferenças (além dos PNEEs) no contexto escolar. Pois, se, para alguns dos coordenadores consultados, a inclusão caracterizava-se como uma "nova realidade", isso pressupõe que, para eles, não existiam excluídos na escola antes da entrada dos PNEEs. Mais do que um fenômeno de hierarquização das diferenças ${ }^{1}$, vemos aqui um fenômeno de negação, como se, para os demais grupos identitários que compõem a escola, não houvesse discriminação, silêncio, segregação ou exclusão.

Os dados levantados pelo questionário de sondagem inicial ficaram comprovados quando os cursistas foram solicitados a posicionar-se sobre o tema. Durante e após o término da parte teórica do módulo, ficou evidente que, para alguns, conceber a inclusão em uma perspectiva de multiculturalidade era algo inédito ou impensado. Discutir questóes étnicas, de gênero, de sexualidade, de religiosidade ou mesmo as que envolviam dificuldades de aprendizagem, repetência e evasão escolar resultou em debates e polêmicas acirradas. Para uns, o enfoque mostrou-se revelador, ampliando-lhes a visão sobre a exclusão na escola; para outros, levou a atitudes de resistência, que evidenciavam posturas arraigadas e, algumas vezes, preconceituosas.

I. Fenômeno em que uns são considerados mais "diferentes" que outros e, portanto, mais excluídos. 
Em relação a este último ponto, vimos que a questão da sexualidade em muitas escolas ainda não possui espaço para discussão. A identidade homossexual ainda é vista por alguns educadores como um desvio, e não como mais um exemplo da pluralidade identitária. Dentre todas as temáticas discutidas, essa foi a que mais polêmica causou e aquela para a qual os cursistas se mostraram menos preparados. Em várias ocasiōes, e em turmas distintas, as opiniōes resvalaram para o preconceito e a discriminação, denotando que a questão em pauta necessita de mais espaço para discussão no campo educacional, se pensarmos em uma educação inclusiva na perspectiva mais ampla proposta pelo multiculturalismo.

Um outro aspecto que levantou polêmica, por não ser um consenso ${ }^{2}$, foi o que ressalta a exclusão daqueles que "não conseguem aprender" e, conseqüentemente, "fracassam" e acabam por ser "expulsos" da escola, mas, no entanto, não são identificados pelos educadores como um grupo de excluídos. Dentro dessa categoria, encontramos alunos com dificuldades de aprendizagem, repetentes, alunos com defasagem idade-série e evadidos. Não descartando que tais problemas possam ter a influência de outros fatores (sociais, econômicos, familiares, de saúde, etc.), procuramos destacar o papel da escola, do currículo e das práticas escolares nesse processo de exclusão. A homogeneização dos currículos, dos métodos e dos instrumentos de ensino e a prática de uma avaliação apenas classificatória, aliadas a uma abstração dos professores em relação à realidade sociocultural de seus alunos, levam a um silenciar das diferenças e a uma ratificação do fracasso escolar (Canen, 1997).

Foi interessante notar que, ao mesmo tempo que as discussóes sobre os diversos grupos excluídos surgiam no desenrolar do módulo, um outro aspecto emergiu de uma forma muito contundente: a consciência de que o grupo de coordenadores pedagógicos em questão também se sentia um grupo excluído no espaço escolar. Tal situação se configurava para os cursistas, uma vez que os mesmos alegavam não possuir, dentro das escolas, um espaço claro de atuação e um reconhecimento da sua importância. Havia uma clara crise de identidade no grupo: o que era ser coordenador pedagógico? Quais suas atribuições na escola? Qual sua importância para a escola? O sentimento de exclusão que assolava o grupo e que emergia constantemente nos debates durante as aulas serviu como um fator de integração que acabou por contribuir, por meio de um processo de identificação, para a construção de uma identidade coletiva e institucional (Canen \& Canen, 2005a).

2. O não-consenso caracterizou-se na medida em que alguns cursistas não consideravam o fracasso escolar como uma forma de exclusão. Para eles, isso se constituía como um fato normal no processo escolar, em que o aluno e a família são considerados os culpados pelo resultado. 
Impactos multiculturais do módulo: pesquisadores em ação...

Ao término de cada encontro, eram levadas, para serem feitas "em casa", uma auto-avaliação e uma pesquisa-ação, que deveriam ser desenvolvidas e trazidas no encontro seguinte. Essa etapa tinha, como objetivo, fazer com que cada cursista fizesse uma reflexão sobre os conceitos estudados, tentando, ao mesmo tempo, implementá-los em suas escolas. Mais do que um processo de auto-avaliação do cursista, essas tarefas serviam como instrumento de avaliação do próprio módulo e do encontro, além de tornar os atores escolares também pesquisadores-em-ação.

A análise dos trabalhos apresentados revelou que os cursistas destacaram, como idéias novas trazidas pelo módulo, as seguintes:

- o conceito de educação inclusiva como um processo abrangente que engloba diversos grupos, além dos PNEEs;

- a concepção de que incluir é muito mais que permitir o acesso à escola. É um direito social e não um ato de benevolência ou assistencialismo;

- a conscientização acerca da existência de um preconceito velado na sociedade e na escola;

- a necessidade de reavaliação de conceitos como "normalidade", "identidade" e "diferença";

- o entendimento de que o "fracasso escolar" é uma forma de exclusão;

- o rompimento com o olhar hierarquizado sobre as diferenças;

- a noção de que a heterogeneidade é a regra e não a exceção no contexto escolar;

- o reconhecimento dos benefícios da educação inclusiva para a sociedade.

Foi possível perceber, por meio das respostas anteriores, que olhar para a inclusão a partir de uma perspectiva multicultural crítica, resultante do módulo trabalhado, significou uma abertura de novos horizontes, inclusive no que se refere à necessidade de rever conceitos pessoais e a desconstrução de discursos naturalizados e preconcebidos sobre as diferenças.

No que diz respeito às idéias consideradas mais polêmicas, foram destacadas:

- a contradição entre a proposta de educação inclusiva feita pelas políticas públicas em educação e a realidade das escolas e dos profissionais da educação - imposição legal versus condiçôes reais;

- a possibilidade de desenvolver atividades inclusivas conjuntamente com o conteúdo a ser trabalhado pela escola, inserindo-as no currículo;

- a questão da identidade sexual; 
- a dificuldade e a resistência em lidar com PNEEs;

- a naturalização e a dissimulação de preconceitos;

- a dificuldade de reconhecer, de aceitar e de trabalhar as "diferenças".

Não descartando a influência de outros fatores importantes, podemos concluir que as respostas listadas parecem evidenciar a necessidade urgente de incorporar, à formação de professores, uma visão multicultural que possa ser traduzida em açôes pedagógicas que contribuam para que as dificuldades e as resistências apontadas em relação à diversidade cultural no contexto escolar sejam minimizadas (Canen, 2005). Nesse sentido, afirmamos que:

Formar o professor multiculturalmente orientado implica, conforme temos argumentado, trabalhar em prol de um modelo de professor apto a compreender o conhecimento e o currículo como processos discursivos, marcados por relações de poder desiguais que participam da formação das identidades. Implica tensionar conteúdos pré-estabelecidos e pretensões a verdades únicas, procurando detectar vozes silenciadas e representadas nesses discursos curriculares, de forma a mobilizar a construção de identidades docentes sensíveis à diversidade cultural e aptas a formular alternativas discursivas transformadoras, desafiadoras do congelamento de identidades e estereótipos. (Canen \& Xavier, 2005, p. 336).

Como resultado da pesquisa-ação implementada pelos cursistas em suas escolas, surgiram aspectos interessantes e, até mesmo, contraditórios. Ao serem questionados sobre se teriam encontrado facilidade ou dificuldade no desenvolvimento da pesquisa-ação proposta em suas escolas, a maior parte dos coordenadores $(72 \%)$ alegou não ter encontrado dificuldades para tal. No entanto, como complemento das respostas, apareceram várias afirmaçooes que pareciam contradizer o que foi exposto inicialmente. Dentre estas, destacamos:

- a existência de resistência dos professores à realização de uma proposta de ação inclusiva;

- o desconhecimento das pessoas sobre o assunto, embora todos soubessem que a questão era importante;

- a dificuldade de identificar os vários grupos socioculturais existentes na escola;

- o caráter polêmico do assunto;

- a existência de clara rejeição aos chamados "diferentes";

- falta de tempo e espaço para implementação da pesquisa.

Contudo, apesar das dificuldades encontradas, foi possível perceber que a proposta desenvolvida no módulo não só conseguiu ressonância junto àqueles 
que estavam envolvidos diretamente no curso, mas também alcançou várias das escolas das quais eles faziam parte. Isso pode ser percebido por meio dos resultados das atividades de pesquisas-ação propostas e dos depoimentos durante os encontros seguintes, como ilustramos a seguir:

No módulo Educação Inclusiva, destaco a idéia de aprofundar o trabalho com a identificação e mudança de posturas discriminatórias epreconceituosas presentes no comportamento de alunos e de professores na escola.

Nosso maior problema é disciplinar. Aponto, no plano de ação que fiz para minha escola por uma educação inclusiva, as seguintes metas: estruturar açôes que conscientizem a comunidade da necessidade de parceria com a escola; criar equipe que colabore no levantamento dos dados e organizaçōes de açōes; relacionar alunos com necessidades de ajudas especificas; organizar encontros para traçar linhas de trabalho em conjunto com a comunidade.

Temos que pensar em curriculo apropriado, adequado, voltado, por exemplo, para o aluno do curso noturno. Lá são alunos excluidos, adultos trabalhadores, de baixa renda [...] muitos oriundos do Norte e do Nordeste [...], planos de ação incluem, no meu entender, sensibilizar um maior número de professores a praticarem em suas aulas atividades de trabalho em grupo, que é uma excelente forma de inclusão de aprendizagem social e integração de diversidades culturais. [...] Deveríamos, também, buscar compreender o porquê de faltas, do abandono escolar, ligando para os alunos, para suas casas. Também, compreender o que dizem suas redaçôes, utilizar trabalhos e atividades para os conhecermos melhor e inclui-los, cada vez mais... Como plano de ação, inicialmente, procuraria informaçôes sobre programas de educação inclusiva para encaminhá-los ao conhecimento do conjunto de toda a equipe. Após a apreciação desses programas, procurariamos traçar estratégias adequadas à escola... Acredito que, inicialmente, seria necessário identificar, na escola, os tipos de preconceito mais freqüentes (preconceito contra o negro, contra a mulher, contra o homossexual, etc). Tal identificação, a principio, poderia ser feita a partir de registros pelo próprio corpo docente e também por questionários aos discentes. Os dados poderiam ser divulgados para debates. Fariamos atividades de sensibilização dos professores para o problema da exclusão (exposição e discussão de casos vivenciados pelos próprios professores, dentro ou fora da escola; apresentação e discussão de filmes sobre o tema). Aproveitaria os representantes de alunos de turmas para discutir a inclusão, com textos sobre o assunto, relatos vividos ou não na escola, situaçôes de preconceito e discriminação. Posteriormente, sugeriria ao Grêmio Estudantil o desenvolvimento de atividades mais amplas, com os próprios estudantes, para fóruns de discussão sobre o tema. 
A partir dos depoimentos, percebe-se que a conscientização quanto à diversidade de identidades culturais e ao papel da escola como organização multicultural (Canen \& Canen, 2005b) foi incrementada com a pesquisa-ação realizada, a partir do módulo trabalhado no curso, dentro dessa perspectiva. Nesse sentido, destaca-se o papel dos cursistas como multiplicadores dos conhecimentos, papel este propiciado pela estratégia adotada no curso, que instigou os próprios participantes a se constituírem como pesquisadores em ação e que levou em conta o diálogo e os saberes docentes para sua concretização. Os exemplos acima indicam que a proposta serviu como propulsora de um repensar e de uma reelaboração da prática pedagógica, levando em conta as identidades docentes e discentes, bem como as da própria comunidade do entorno escolar.

Assim sendo, a partir do que foi apresentado, podemos concluir que as discussóes realizadas a partir do módulo serviram, para muitos dos envolvidos no curso, como fonte de reflexão e de ação no que tange ao trato da educação inclusiva em uma perspectiva multicultural nas escolas. Esse fato evidencia a importância de empreender espaços de formação continuada que possibilitem aos educadores um repensar de concepçóes e a troca de experiências, de modo que estes se sintam participantes, ouvidos e valorizados. Acima de tudo, revela o potencial de ações extensionistas da universidade, não só em seus impactos na escola, mas também como geradora de reflexões e de pesquisas para os atores universitários, reflexões essas centrais para a formação de professores e de pesquisadores no contexto contemporâneo, cada vez mais multicultural.

\section{Conclusões}

$\mathrm{O}$ argumento que desenvolvemos na presente pesquisa foi o de que a educação inclusiva poderia beneficiar-se da perspectiva multicultural, que questiona formas de invisibilidade ou de ocultação das diferenças, de modo a desafiar e superar preconceitos e processos de exclusão de diferentes grupos socioculturais oprimidos, no contexto educacional. Nesse sentido, argumentamos que a extensão universitária, aqui delimitada em termos de ações universitárias no campo da formação continuada de professores e gestores educacionais da rede pública de ensino, pode contribuir para uma visão mais alargada da educação inclusiva e multicultural, propiciando férteis diálogos entre a universidade e a escola.

Partindo dessas reflexões e a partir do multiculturalismo em sua vertente mais crítica, neste trabalho procuramos analisar o processo de inclusão escolar a partir de uma ótica mais abrangente e desafiadora, que ultrapassa a abordagem a-crítica da mera aceitação das diferenças. Buscamos compreender como essa temática tem sido trabalhada nas escolas públicas do Rio de Janeiro em 
suas concepções e práticas pedagógicas, procurando evidenciar de que forma as ações que caracterizam a educação inclusiva no cotidiano dessas escolas podem encontrar espaços para uma visão multicultural mais crítica, tomando como base da reflexão o caso de uma pesquisa-ação desenvolvida na formação continuada de professores, no Rio de Janeiro.

O trabalho inclusivo, em uma perspectiva multicultural, conforme trabalhado no curso de formação continuada em questão, extrapola a mera inserção e aceitação das diferenças ou a reestruturação física do espaço escolar. Ele pressupõe a superação de preconceitos e barreiras atitudinais entre todos os integrantes da comunidade escolar, objetivando a construção conjunta da escola como uma organização multicultural; como um ambiente em que o questionamento, o diálogo, a cooperação, a solidariedade, o respeito às diferenças e a justiça social sejam o motor de todas as ações.

Promover a pesquisa-ação na perspectiva multicultural, no curso em pauta, significou discutir sua importância no contexto de nossas escolas públicas, buscando o diálogo entre a produção do conhecimento na área e a prática dos profissionais da escola envolvidos. A análise dos dados evidenciou que o olhar sobre a educação inclusiva, por parte dos profissionais da educação, estava inicialmente impregnado por uma visão de inclusão restrita à adaptação dos portadores de necessidades educacionais especiais à escola. O módulo buscou problematizar tal concepção, alargando o conceito de inclusão e inserindo-o nos questionamentos multiculturais sobre identidade e diferença; normalidade e anormalidade; inclusão e exclusão, de modo a fomentar o diálogo das diferenças e a valorização da diversidade cultural - central para a formação de futuras gerações aptas a valorizar essa diversidade, em um mundo marcado por intolerâncias e conflitos.

\section{Referências bibliográficas}

CANEN, Alberto Gabbay \& CANEN, Ana. Organizaçôes multiculturais. Rio de Janeiro: Ciência Moderna, 2005b.

CANEN, Ana. Competência pedagógica e a pluralidade cultural: eixo na formação de professores? Cadernos de Pesquisa, São Paulo, n.102, p.89-107, nov./1997.

. Refletindo sobre identidade negra e currículo nas escolas brasileiras: contribuições do multiculturalismo. Série Estudos - Periódico do Mestrado em Educação da UCDB, Campo Grande, n.15, p.49-57, jan./jun. 2003.

. Pesquisando multiculturalismo e pensando multiculturalmente sobre pesquisa e formação docente: uma experiência de currículo em ação. In: REUNIÃO ANUAL DA ANPED, 28, 2005, Caxambu, MG, 2005. 
CANEN, Ana \& CANEN, Alberto Gabbay. Rompendo fronteiras curriculares: multiculturalismo na Educação e outros campos de saber. Revista Curriculo sem Fronteiras, v. 5, n. 2, pp. $40-49,2005$ a.

CANEN, Ana \& MOREIRA, Antonio Flávio Barbosa. Reflexões sobre o multiculturalismo na escola e na formação docente. Educação em Debate. Fortaleza, ano 21, v. 2, n. 38, p. 12-23, 1999.

CANEN, Ana \& SANTOS, A. R. dos. Construção e reconstrução de identidades docentes no âmbito da formação continuada: possibilidades curriculares e didáticas multiculturais. Revista Brasileira de Estudos Pedagógicos, Brasília, v. 87, n. 217, pp. 339-349, 2006.

CANEN, Ana \& XAVIER, Giseli Pereira de Moura. Multiculturalismo, pesquisa e formação de professores: o caso das Diretrizes Curriculares para a Formação Docente. Ensaio: Avaliação e Políticas Públicas em Educação. Rio de Janeiro: Fundação Cesgranrio, v. 13, n. 48, p. 333344, jul./set. 2005.

D’ADESKY, Jacques Edgard François. Racismos e anti-racismos no Brasil. Pluralismo étnico e multiculturalismo. Rio de Janeiro: Pallas, 2005.

MIRANDA, M. G. de \& RESENDE, Anita Cristina Azevedo. Sobre a pesquisa-ação na Educação e as armadilhas do praticismo. Revista Brasileira de Educação, Rio de Janeiro, v. 11, n. 33, pp. 511-518, 2006.

SILVA, Tomaz Tadeu da. A produção social da identidade e da diferença. In: SILVA, Tomaz Tadeu da (Org.). Identidade e diferença. A perspectiva dos estudos culturais. Petrópolis: Vozes, 2000. p.73-102.

SKLIAR, Carlos (Org.). A invenção da e a exclusão da alteridade "deficiente" a partir dos significados da normalidade. Educação e Realidade - Das diferenças. Porto Alegre: Faculdade de Educação/UFRGS, v. 24, n. 2, p.15-32, jul./dez. 1999.

. Inclusão ou exclusão. In: SHIMIDT, Saraí. A educação em tempos de globalização. Rio de Janeiro: DP\&A, 2001. p.31-40.

XAVIER, Giseli Pereli de Moura. Educação inclusiva, módulo IV. Formação continuada para coordenadores pedagógicos, Programa Sucesso Escolar. Secretaria de Estado de Educação do Rio de Janeiro/Universidade Federal do Rio de Janeiro, 2005.

Recebido em 05 de novembro de 2007 e aprovado em 22 de agosto de 2008. 